\title{
Analysis of the Pattern of Land Degradation in Okaba, Kogi State, Nigeria
}

\author{
Shaibu. M. Hassan, Jibril A. Edicha \& UmoruKabiru
}

\begin{abstract}
The study examined the pattern of land degradation in Okaba using GIS and remote sensing techniques. The study area is located between latitude $725^{\prime}-731^{\prime} \mathrm{N}$ and Longitude $740^{\prime}-746$ ' E and covers approximately $122.7 \mathrm{~km}^{2}$. The satellite data (landsat: $1998,2002,2007$ and 2012) together with other geospatial datasets were used to quantify different categories of land degradation. The results were validated in the field. Land use/ land cover of the study area was determined in order to see the effects of land use on land degradation. Normalized Differential Vegetation Index (NDVI) and Tasseled Cap indicators of the area were determined from Landsat data. Landsat along with other secondary data were analyzed to create various thematic maps, viz., land use, vegetation, and soil used in modeling land degradation in Okaba. The Land use/cover, NDVI, Tasseled Cap Brightness (TCB), Tasseled Cap Wetness (TCW) and Tasseled Cap Greenness (TCG) were integrated to assess the degradation scenario in the study area using the Idrisi Selva 'Reclasstool' and ArcGIS 10'Spatial analyst tool'. The results reveal that bareground increases throughout the study epoch while vegetation decreases. The findings of this study revealed that $42.1 \%$ of land is undergoing different categories of land degradation such as soil erosion and devegetation.
\end{abstract}

Key words: Land degradation, NDVI, Land use/land cover

\section{Introduction}

Land degradation is increasing in severity and extent in many parts of the world, with more than $20 \%$ of all cultivated areas, $30 \%$ of forest and $10 \%$ of grassland undergoing degradation (Bai, et. al., 2008). Millions of hectares of land per year are being degraded in all climatic regions. It is estimated that 2.6 billion people are affected by land degradation and desertification in more than a hundred countries, influencing over $33 \%$ of the earth's land surface (Adams and Eswaran, 2000). This is a global development and environmental issue highlighted at the United Nations Convention to combat desertification, the convention on biodiversity, the Kyoto protocol on global climate change and the millennium development goals (UNCED, 1992; UNEP, 2008). In subSaharan Africa, land degradation is especially widespread affecting 20-50\% of land and some 200 million people. Land degradation is also widespread and severe in Asia and Latin America as well as other regions of the globe. The immediate causes of land degradation. is inappropriate land use that leads to degradation of soil, water, and vegetative cover and loss of both soil and vegetative biological diversity, affecting ecosystem structure and functions (Snel and Bot, 2003). Land degradation encompasses 
the whole environment but includes individual factors concerning soils, water resources (surface, ground), forests, croplands and biodiversity (FAO, 2005).

Kogi state is endowed with abundant mineral resources of international value, including coal, limestone, gypsum, gemstones, and iron ore. The state's major coal fields are located in Okaba, Okobo and Odagbo. The open cast mining method is used in extracting coal in the study area. Mining is a major economic activity in many developing countries (Tauli-Corpuzv (1997) and UNEP (1997) and producing enormous quantities of waste that can have deleterious impacts for decades (UNEP, 1997). The environmental deterioration caused by mining occurs mainly as a result of inappropriate and wasteful working practices and rehabilitation measures. Mining has a number of common stages or activities, each of which has potentially-adverse impacts on the natural environment, society and cultural heritage, the health and safety of mine workers, and communities based in close proximity to operations (Moody R. and, Panos 1997). The social and environmental impacts are more pervasive in regions where operations are newlyestablished or are closing down. It is imperative from the above that the mineral extraction process must ensure return of productivity of the affected land and hence the need for this study.

Although the coal deposit in the study area is of immense economic value, however, the mining processes have posed a negative impact on the environment. Adequate and up todate information about these impacts and their effects are therefore needed for effective planning, problem solving and decision making. In Okaba, such adequate and up to-date information that monitor land degradation is not available despite the level of degradation in the area. The first reason for this is the fact that there are no sufficient studies that monitor land degradation in Okaba and the problem associated with them. Secondly, the few studies available are subjective and used the old conventional manual methods of data acquisition and analysis which make updating of data for monitoring the extent of land degradation difficult. Thirdly, most of the studies on land degradation in Okaba did not cover the entire Okaba but cover mine site in isolation. For example, (Umoru, 2008) studied the problems and prospects of Okaba coal mining industry in Ankpa Local Government, Kogi State, with the aid of questionnaire survey and Oral interview, Charles, et.al. (2009) studied the hydrological characteristics of surface mine spoil in Okaba Coalfield of Kogi state. The study evaluated geological formation of the coal field; topography of the mine site and the lithological and hydrological components of mine site using borehole sections, map based analysis and field measurement and concluded that surface runoff (along with the spoil water from coalfields) drawn directly into natural drainage system (streams/rivers). Omali and Egboka (2011) also focused on the physicochemical assessment of water around Okaba coalmine. He argued that mining activities discharge toxic materials into water bodies in the area thereby affecting water quality. None of these studies investigated the relationships among biophysical attributes of degraded landscapes in the area, which are critical in guiding sound decisions with regard to types and magnitudes of rehabilitation practices an area would require. None of them also applied geo-informatic techniques 
which allow for regular updating of data and information for monitoring and modeling changes. This study therefore is an attempt to fill these gaps.

\section{The Study Area}

Okaba, is about $20 \mathrm{~km}$ north east of Ankpa, and serves as the headquarters of Ojoku district in Ankpa Local government area of Kogi State. Okaba lies between latitudes $7^{\circ}$ $25^{\prime} \mathrm{N}$ and $7^{\circ} 31 \mathrm{~N}$ of the equator and between Longitude $7^{\circ} 40^{\prime} \mathrm{E}$ and $7^{\circ} 46^{\prime} \mathrm{E}$ of the Greenwich Meridians (Fig.1). The study area shares a common boundary with Enjemain Ankpa local government area to the North, Ojoku in Ankpa Local Government Area of Kogi State to the South and Awo in Ankpa Local Government to the West and Benue state to the east.

The climate of the study area, is tropical wet and dry (Faniran and Ojo, 1980). The code of the climate is "A.W" in the Koppen's climatic classification system. Okaba is one of the district headquarters in Ankpa local government area, and falls within the Ankpa vast Plateau. The topography of the areas is undulation with slope of about $20-25^{\circ}$ said to be the remains of the vast Jos Plateau (Charles et. al. 2009). Okaba, is made up of flat land areas towards the west and vast undulating plain mixed with gentle sloping hills to the east. The average height of the hills being between 200-300 meters high (Charles et.al.,2009). The study falls within the geologic Fonnations known as the Coal Measures, consisting of Mamu Formation and Ajali Formation.

The settlement pattern in Okaba is linear settlement, where most houses are found along the road linking the town to the coal mine. The settlement is concentrated on a valley plain in the western part, with the hilly area on the eastern part of Okaba with average height of about 200-250 meters high are left uninhabited (Umoru, 2008)

The vegetation of the study area falls within the guinea savanna vegetation. It is basically composed of grass savanna and deciduous trees. Also, it has become derived savanna as a result of human activities like agriculture, mining, and deforestation. The vegetation is dominated presently by short grasses with scattered trees, typical of a derived savannah with patches of grassy woodland, along with patches of shrubs and herbs interspersed with a mixture of light and gallery forest. The tree species found in the study area include; Chlorophora excelsa (Iroko) Tectona grandis (Teak), Elaeis Guineensis (Palm tree) Gmelina arborea among others (Umoru,2008).

The prevalent land use and socio-economic activity of the study area includes farming, mining among others. 
Figure: Map of Nigeria showing Kogi State and Map of Kogi State Showing Ankpa Local Government

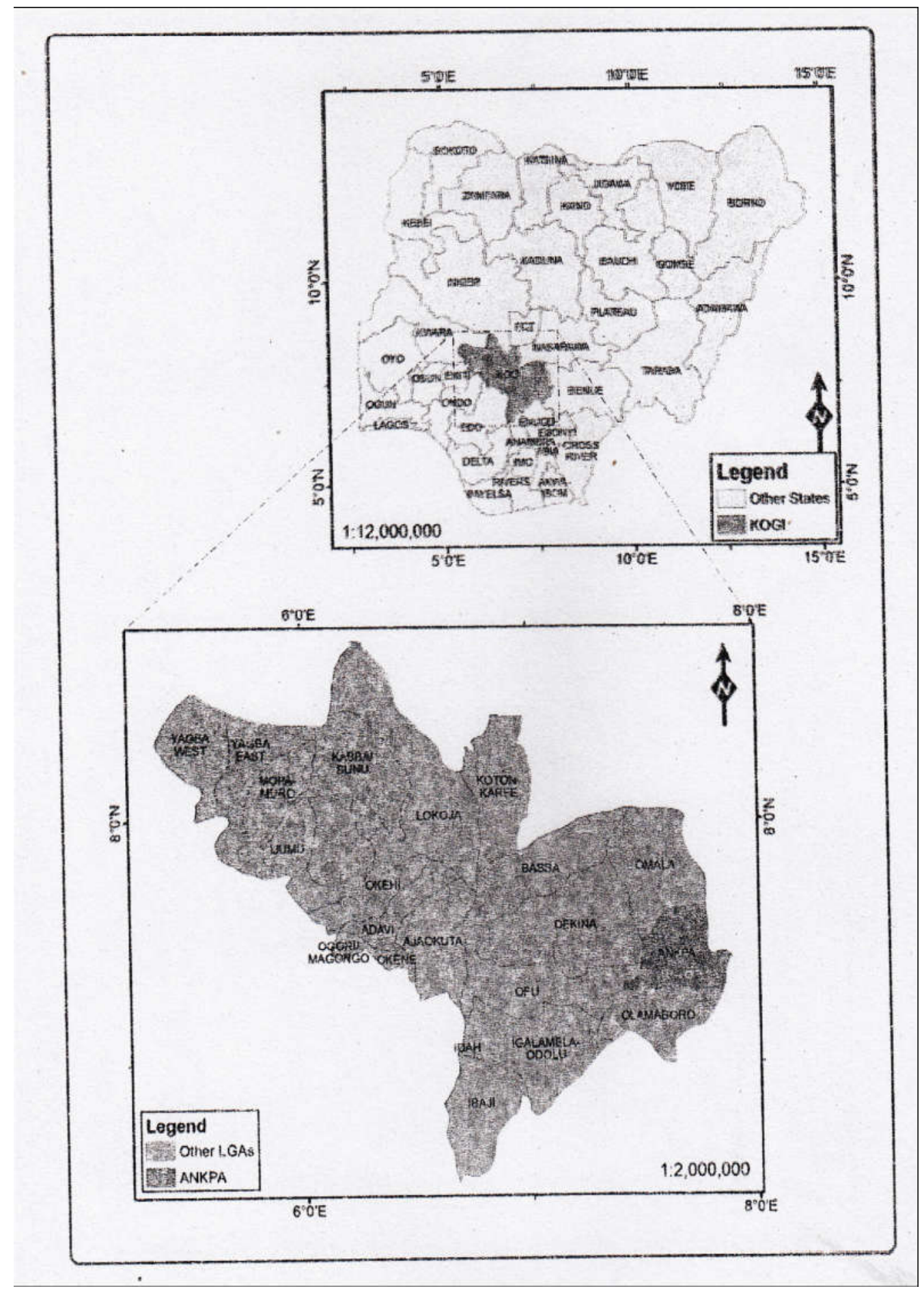

Annals of the Social Science Academy of Nigeria, No 20, 201575 


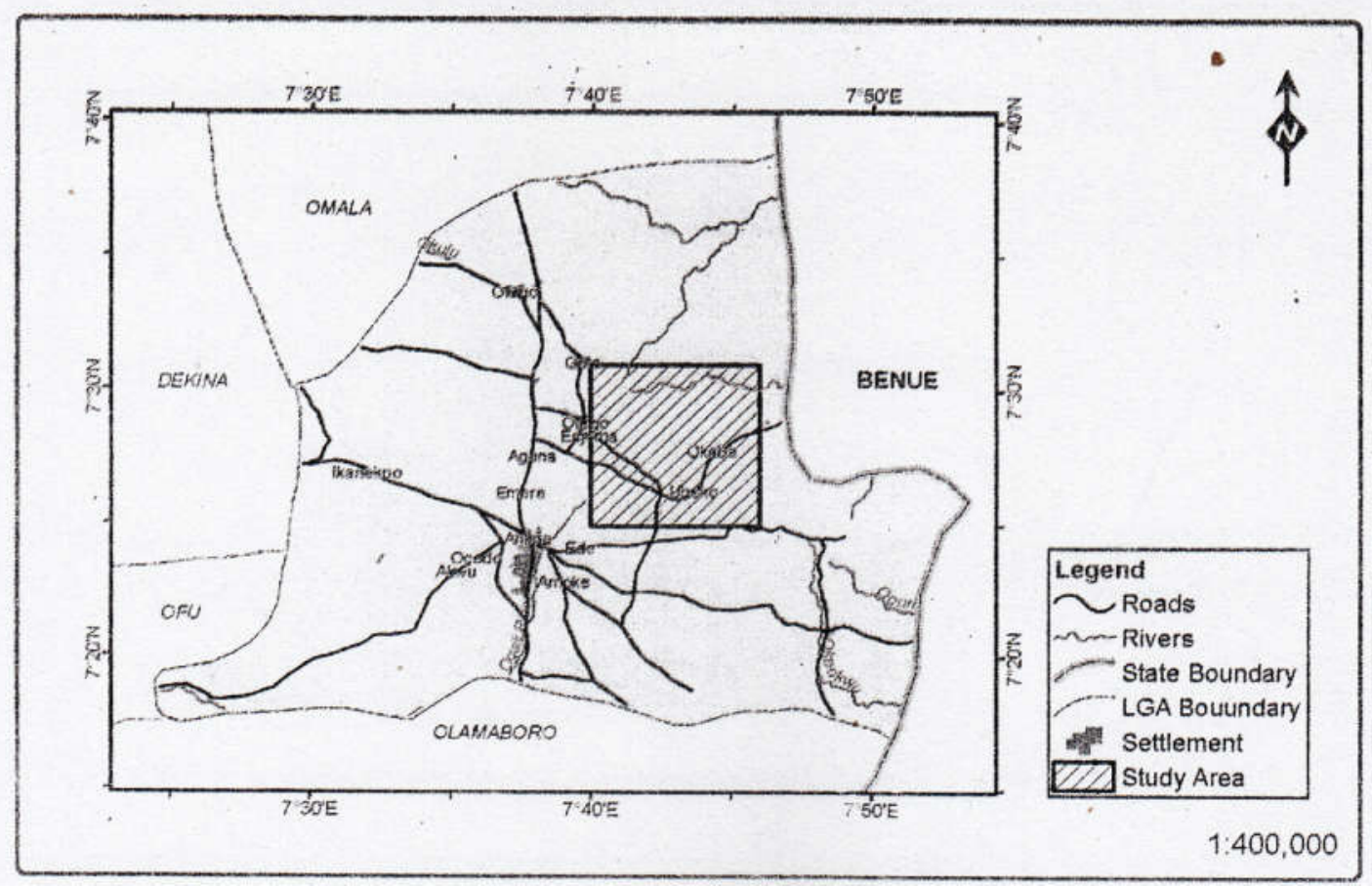

Figure 2: Map of Ankpa Local Government showing the Location of the Study Area

\section{Methodology}

The materials required for this study include:

i. LandsatETM of 1998-2012 (that is 4 epochs at 5 years interval)

ii. Okaba Topographic Map

iii GPS Coordinates

Landsat imageries were the primary data type used for the comprehensive classification of the study area as well as for extracting relevant biophysical indicators and quantifying the trend of land degradation for the study area. The study area is located on Path 188, Row 055 of Landsat flight path. The Topographic map showed the designated uses and elevation of the study area. The geographic coordinates of the various locations of interest in the study area served to provide the necessaiy Geo-referencing.

The Landsat imageries were downloaded from the official website of Global Land Cover Data Facility (GLCF)-http://glcf.umiacs.umd.edu. while the topo sheet was acquired from the National Centre for Remote Sensing Jos. The GPS Coordinates were 
collected by field work with the aid of a GPS handheld receiver. Also, ArcGISIO and IdrisiSelva were used for performing the various digital image processing operations and spatial analyses of this study. A Garmin 97 hand held GPS was also used in this research for field data collection and ground-truthing.

\section{Data Processing}

The data processing procedure include pre-processing which entails image processing of the Landsat imageries used for this study and requires the gap-filling of the gaps that resulted from the failure of the on-board line-scan-corrector (LSC) for imageries collected after May 2003. An ENVI software extension dubbed 'Landsat gap-fill tool' was used for this gap filling. Further preparation of the gap-filled Landsat imageries entailed sub-setting (clipping) the entire Landsat scene to the study area section of this research. Atmospheric correction was performed to remove the effects of solar illumination differences and other atmospheric anomalies (like atmospheric path reflectance, electromagnetic scattering/absorption) from the imageries was completed with the 'ATMOSC' module (IDRISI $17.0>$ 'Image Processing' > 'Restoration' > 'ATMOSC') using the 'Dark Object Subtraction' atmospheric correction model. There was no need for any geometric correction because this had effectively been done from source. Pan-sharpening to enhance the spatial resolution of the satellite imageries was also carried out.

\section{Method of Data Analysis}

The land use/cover classification followed the usual procedure of supervised land use/ cover classification of remotely sensed imageries. It commenced by selecting the classification scheme that determines the types and number of Land use/cover classes to classify for the study area. Some of the existing land use/cover classification schemes include Anderson (1976) Land use/cover classification scheme for use with remote sensing imageries, However, this study employed a modified version of the Anderson (1976) classification scheme at the Level 1, because of its simplicity and easy modification for adaptation to the Land use/cover classification requirements of this research and bearing in mind that it was specifically designed for the Landsat satellite series that is the main dataset used for this study. Such modifications is imperative as not all the land use/cover classes present on that scheme were discernible in the study area, (like water bodies and tundra among others) coupled with the fact that certain land cover types (like debris) were discernible in the study area but not captured on the Anderson (1976) classification scheme. The five Level 1 Land Use/Cover classes discernible in the study area and adopted for this study were bare ground, Woodland, grassland, built-up areas and rock debris. Training sites were identified for this Land use/cover classes based on field work complemented by a visual image interpretation. These sites were then used to develop the spectral signatures for the supervised classification. The signature development was completed in Idrisi using the, 'MAKESIG' module ('Idrisi 17.0' > 'Image Processing' > 'Signature Development' 
'MAKESIG'). These developed spectral signatures from the training sites together with the six (6) optical bands from the Landsat ETM+ satellite imagery were the inputs to the Maximum Likelihood Classification (MLC) algorithm adopted for this stucfy. The MLC algorithm was operationalized in Idrisi through the 'MAXLIK' module ('Idrisi 17.0' > 'Image Processing' > 'Hard Classifiers' > 'MAXLIK'). The supervised classification procedure described above was repeated for the Landsat Imageries of the four (4) epochs considered for the study (1998, 2002, 2007 and 2012). Furthermore, post classification technique was also employed in this study.

Land degradation as conceptualized in this study is a dynamic process of particularly the increasing anthropogeneity of an area (or conversely, the reduction in the naturalness) of an area over two study epochs, the first stage in the post-classification comparison involved the ranking of the land use/land cover classes of the classified Landsat imageries according to their intensity of human use considering the works of Symeonakis and Drake (2004) and Kiage et al (2007). A direct ranking of the land use/land cover was employed such that the higher the intensity of Land use, the higher the rank value assigned. Table 1 shows the ranks assigned to the various land uses identified for this study. The ranking was also, completed in the Idrisi software environment using the 'RECLASS' Module ('Idrisi 17.0 > 'GIS Analysis' > 'Database Query'> 'RECLASS').

Table 1: Land Use/Cover Ranking based on the Intensity of Human Use

\begin{tabular}{|l|c|}
\hline Land Use/Cover & Biophysical Rank \\
\hline Built up & 5 \\
\hline Bare ground & 4 \\
\hline Rock debris & 3 \\
\hline Grassland & 2 \\
\hline Woodland & 1 \\
\hline
\end{tabular}

Although this biophysical ranking of land use/cover direct ranking was done to correspond with increasing intensity of human use of an area as typified by the associated land use/ cover of the same area, the ranking was done based on works of Symeonakis and Drake (2004) and Kiage et al (2007). Complications could arise as differentiating the intensity of human use between certain Land use/cover classes may be questionable. Despite this, since land degradation is deduced to have occurred mainly by an increase in the rank assigned to the original land use/cover class, the original biophysical rank assigned may not substantially impact negatively on the reliability of the results derived from this sort of land degradation analysis.

In the same vein, analysis of land degradation as a function of changes in land use/cover between two study dates, the difference between the ranked LU/C images from the preceding section was computed. In essence, the ranked image of an earlier date was 
subtracted from the ranked image of a later date. The Idrisi 'OVERLAP' module ('Idrisi 17.0'> 'CIS Analysis' > 'Database Query' > 'OVERLAY') was used to complete the image differencing using the subtraction operator.

The implication of this operation is that a resulting value of zero indicates an area has remained undegraded over the two study epochs being studied; while with increasing value of the result comes increasing intensity of land degradation in an area as shown in Table 1 above. This implies that the highest land degradation value of four (4) will be recorded for the most intensive land degradation of an area. This is expected to happen mainly when woodlands (with a rank value of' 1 ') in an earlier year changes to built-up area (with a rank value of ' 5 ') in a later year (since 5-1=4). The main strength of this analysis is that it does not simply provide a binary measure of land degradation ('degraded' or 'not degraded'); it also captures the intensity of degradation on the ordinal measurement scale. Similarly, the biophysical indicators of this study were derived as show in figure 3. 


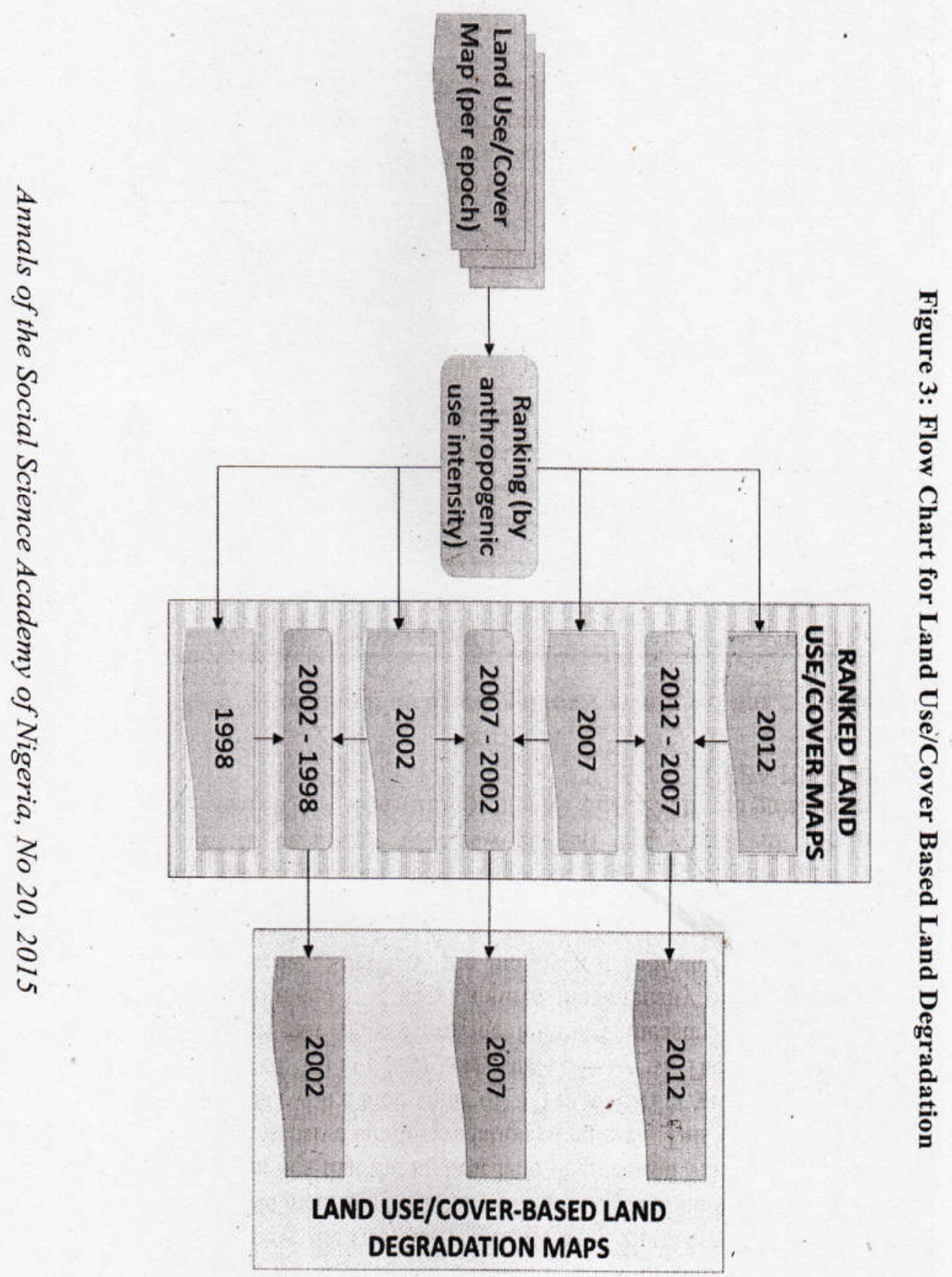


Figure 4: Flow Chart for Extraction of Biophysical Indices

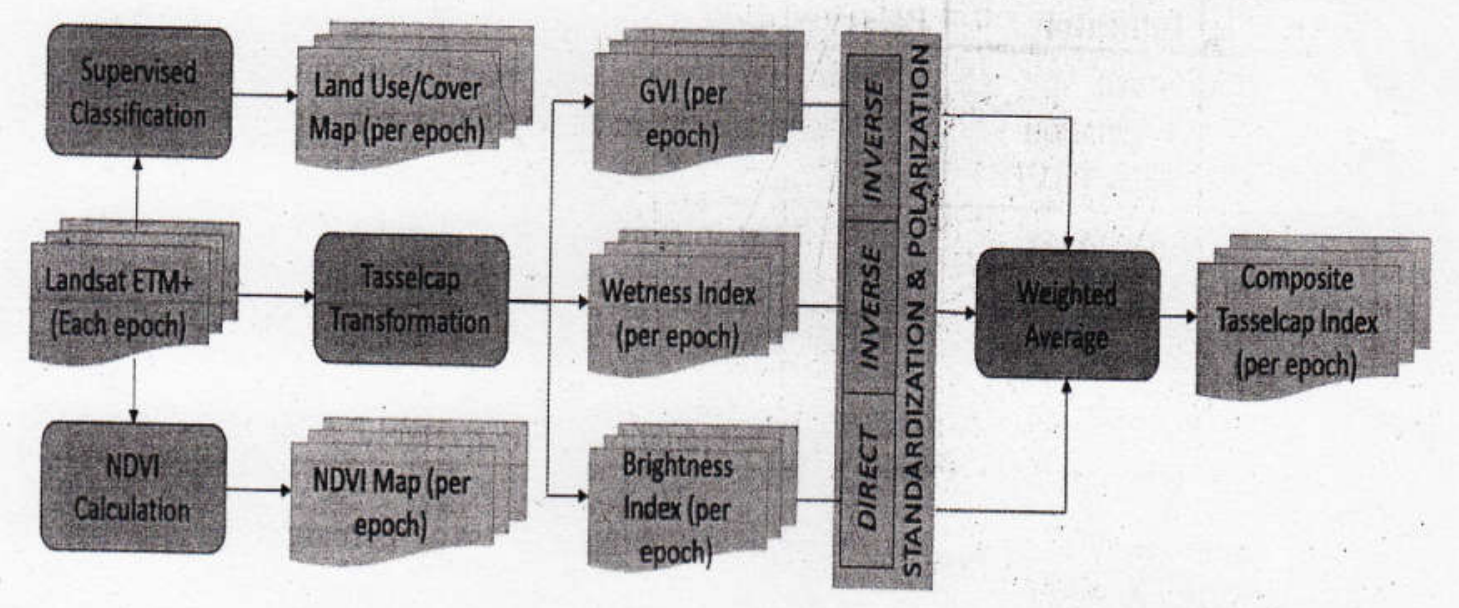

The biophysical indicators employed in this study as very good explicators of land degradation are the NDVI, the Wetness Index, The Greenness Index, the Brightness Index and land cover. Note that the Wetness, Greenness and Brightness Indices are all derivatives of the tassel cap transformation.

In this study, NDVI was determined using bands 4(NIR) and 3(Red) of Landsat respectively.The NDVI for all the study epochs was extracted using the 'VEGINDEX' module ('Idrisi 17.0' > 'Image Processing ${ }^{1}>$ 'VEGINDEX'> 'NDVI'). The resulting NDVI values were then standardized to ensure that the NDVI values across the four study epochs were directly comparable. Further analysis was done with respect to Tassel Cap Indicators.

Tassel Cap Transforms the six land-sat ETM bands into three indicators of known characteristics; soil brightness (TCB), Vegetation greenness (TCG) and soil/vegetation wetness (TC W). Tasseled cap wetness was used to determine the amount of moisture being held by the vegetation or soil, thus termed wetness (Christ, 1985). Connecting to Tassel Cap indicator is composting the Tassel cap Indicators. The three (3) tassel cap indicators for each year were aggregated to form a composite tassel cap biophysical indicator per year. The procedure for the aggregation was accomplished using polarization and standardization of indicators. To determine the relationship between land degradation and biophysical indicators, table 2 is employed. 
Table : Relationship between Land Degradation and Biophysical Indicators

\begin{tabular}{|l|l|l|l|}
\hline S/No & Indicator & Polarity & Explanation \\
\hline 1 & $\begin{array}{l}\text { Green } \\
\text { Ve getation } \\
\text { Index }(\mathrm{GVI})\end{array}$ & Inverse & $\begin{array}{l}\text { With decreasing vegetation comes increasing land } \\
\text { degradation of any area and vice versa }\end{array}$ \\
2 & $\begin{array}{l}\text { Brightness } \\
\text { Index }\end{array}$ & Direct & $\begin{array}{l}\text { With increasing exposure of soil comes increasing } \\
\text { land degradation and vice versa }\end{array}$ \\
& Wetness & Inverse & $\begin{array}{l}\text { With decreases in the moisture content of any } \\
\text { earth surface material comes increases in land } \\
\text { Index }\end{array}$ \\
& & & degradation and conversely. \\
\hline
\end{tabular}

Because land degradation was conceived as a dynamic process of increase in the intensity of human use, figure 4 describes how land degraded was analyzed based on this concept.

Figure 5: Flow Chart for NDVI and TASSCAP Based Land Degradation

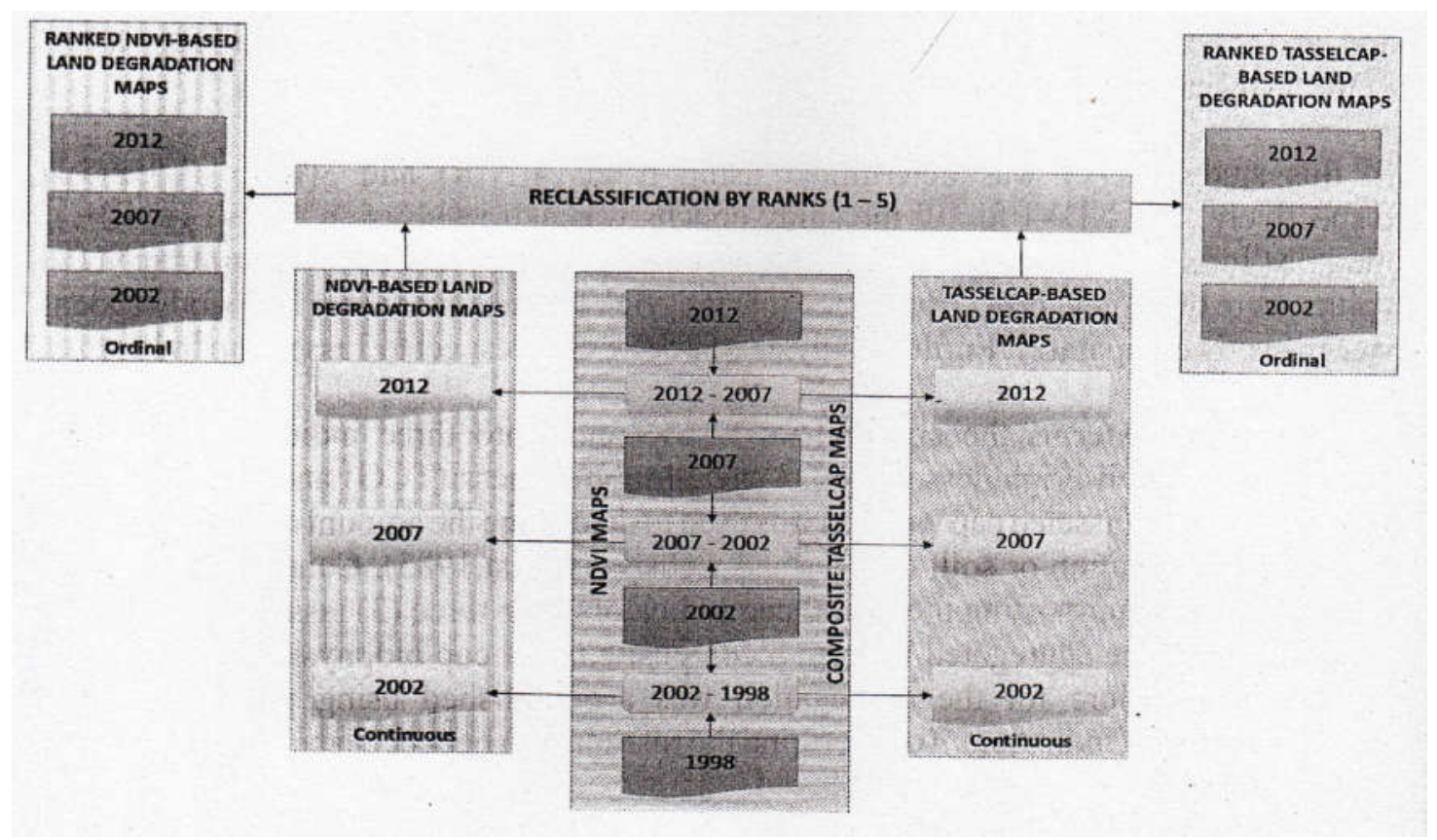

To determine the land degradation of any year based on the NDVI biophysical indicator, the standardized NDVI raster for an earlier year was arithmetically subtracted from the standardized NDVI raster of a later year to derive the land degradation as that later year. This implies that because only four study epochs were considered in this research, it was only possibly to derive land degradation for the three later years $(2002$, 
2007, and 2012). As with the remaining indicators' subtraction in this section, the 'First - Second' overlay function Idrisi 17.0 > 'GIS Analysis'> 'Mathematical Operators'> 'OVERLAY'>'First Second') was used to effect the raster subtraction. For example, to map land degradation for year 2002, the standardized NDVI image of 1991 was subtracted from the standardized NDVI image of 2002. On the result of such subtraction, pixels with decreased NDVI values (as connoted by negative subtraction results) indicate places of vegetation loss; hence places of land degradation. The opposite holds for places of increased NDVI values (as denoted by positive subtraction results). Furthermore, the intensity of land degradation can be ranked based on the magnitude of negative values recorded from the subtraction - with lower negative values signifying a higher order of land degradation than a lower negative value. This was the premise for classifying (ranking) land degradation for this study.

Similarly, the image differencing for the tasselcap composite indicator is also derived. Since the Tassel cap indicators had been polarized such that higher values indicated a more intensive anthropogenic use, the result of subtraction from an earlier year's indicator raster is different to that described for the NDVI indicator above. In essence, the result for the case of the Tassel cap indicator subtraction is the opposite of what obtained for the NDVI subtraction. In this case, positive values on the resulting raster indicated increased intensity of anthropogenic activities across a' given two years; hence, land degradation was interpreted to have taken place. On the contrary, negative resulting values from the image subtraction, indicates a reduction in anthropogenic activities across the two years considered; hence, the converse of land degradation can be said to have taken place. And as with the case of the NDVI (though the opposite obtains in this case,) with increasing positive subtraction results comes increased land degradation and vice versa.

To illustrate the foregoing explanations more lucidly, land degradation as at year 2002 was analysed by subtracting the composite Tassel cap indicator of 1998 from that of year 2002. Positive values on the resulting raster indicate land degradation with higher values corresponding to a higher order of land degradation and vice versa.

The premise for classifying land degradation has already been established in NDVI standardization and Tassel Cap composite indicator differencing for the three main categories of indicators considered in this research (Land Use/Cover, Tasselcap transformation and NDVI). For all these three main categories indicators, the result of subtracting the raster of an earlier year from that of a later year served as the effective land degradation raster maps upon which the classification in this section was based. The overall aim of the classification here was to transform the land degradation raster from its original interval level of quantification to discrete categories on the ordinal measurement level to aid better and easier interpretation of the results.

Since all the indicators had been standardized, the same class intervals were used to classify each of the three epochs of each indicator to ensure consistency and the direct 
comparison of results across the study years considered. Each indicator was classified into 5 discrete levels of Land degradation after the Likert scale. In all cases, an equal class interval was used to classify the land degradation. For each series of indicator, the maximum and minimum land degradation values (positive or negative values) were collected across the three study epochs, and then class breaks were determined such that 
Classifying Land Degradation

Figure 6: Flow Chart for Classification of Land Degradation

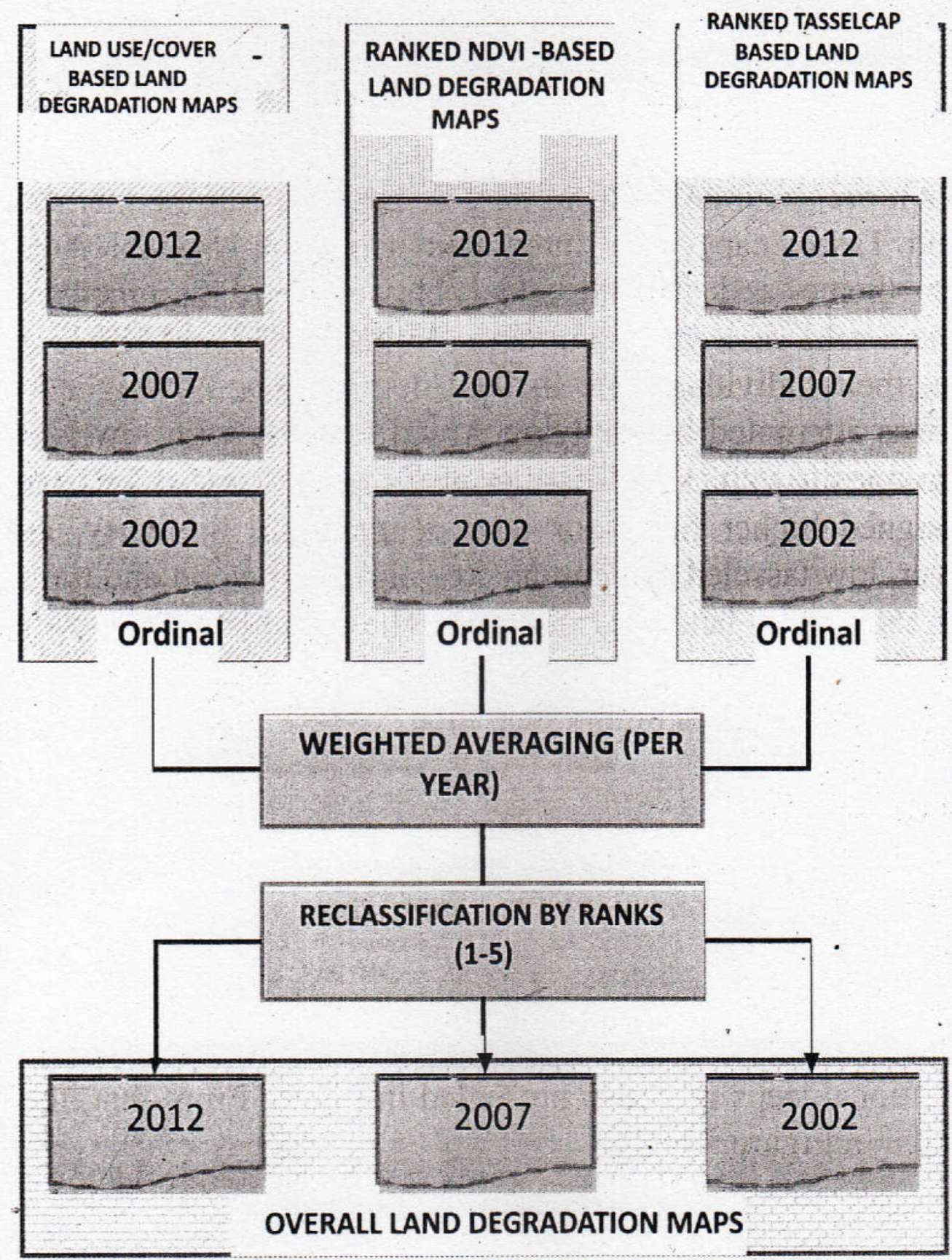

Annals of the Social Science Academy of Nigeria, No 20, 2015 
five classes could emanate from the overall class range considered. For instance, for the standardized NDVI indicator, positive values in the result of the land degradation differencing indicates that no land degradation took place, as such all positive values including zero were recorded non-degraded. The foregoing explanation and illustration served to guide the implementation of the classification in the Idrisi software environment through the use 'RECLASS' module (Idrisi 17.0> 'GIS Analysis'> 'Database Query' > 'RECLASS').

To determine a more accurate status of land degradation, all the themes (Ndvi, land use/ land cover and Tassel cap) were integrated using the 'Spatial Analyst Module' of ArcGIS. .Each theme and its individual classes were assigned weight and rank considering the works of Symeonakis and Drake (2004) and Kiage et al (2007), and were based on their individual role in land degradation. A weighed overlay analysis methodology was attempted by applying ArcGIS. Areas with low Ndvi values, higher tasseled cap composite values and bareground and rock and debris land cover classes, have been assigned higher ranks for land degradation. Similarly, areas with a high vegetation cover, low tasseled cap composite values and woodland type land cover were assigned low ranks for land degradation. The resultant composite coverage was classified into five classes: (1) nondegraded, (2) slightly degraded, (3) Moderately degraded (4) Degraded and (5) highly degraded.

\section{Discussion of Results}

\section{Land use/land covers characteristics of the Study Area}

The procedure by which the detailed Land use/cover classes for the study where derived have been explained elaborately in the methodology. A flow chart showcasing the necessary operational steps was also presented in Fig. 6. From that, the Land use/coyer maps is presented in Figure 7 below. 
Figure 7: Classified Land Use/Cover Maps (Top-right, 1998, Top-left, 2002, Bottom-left, 2007 and Bottom-right,
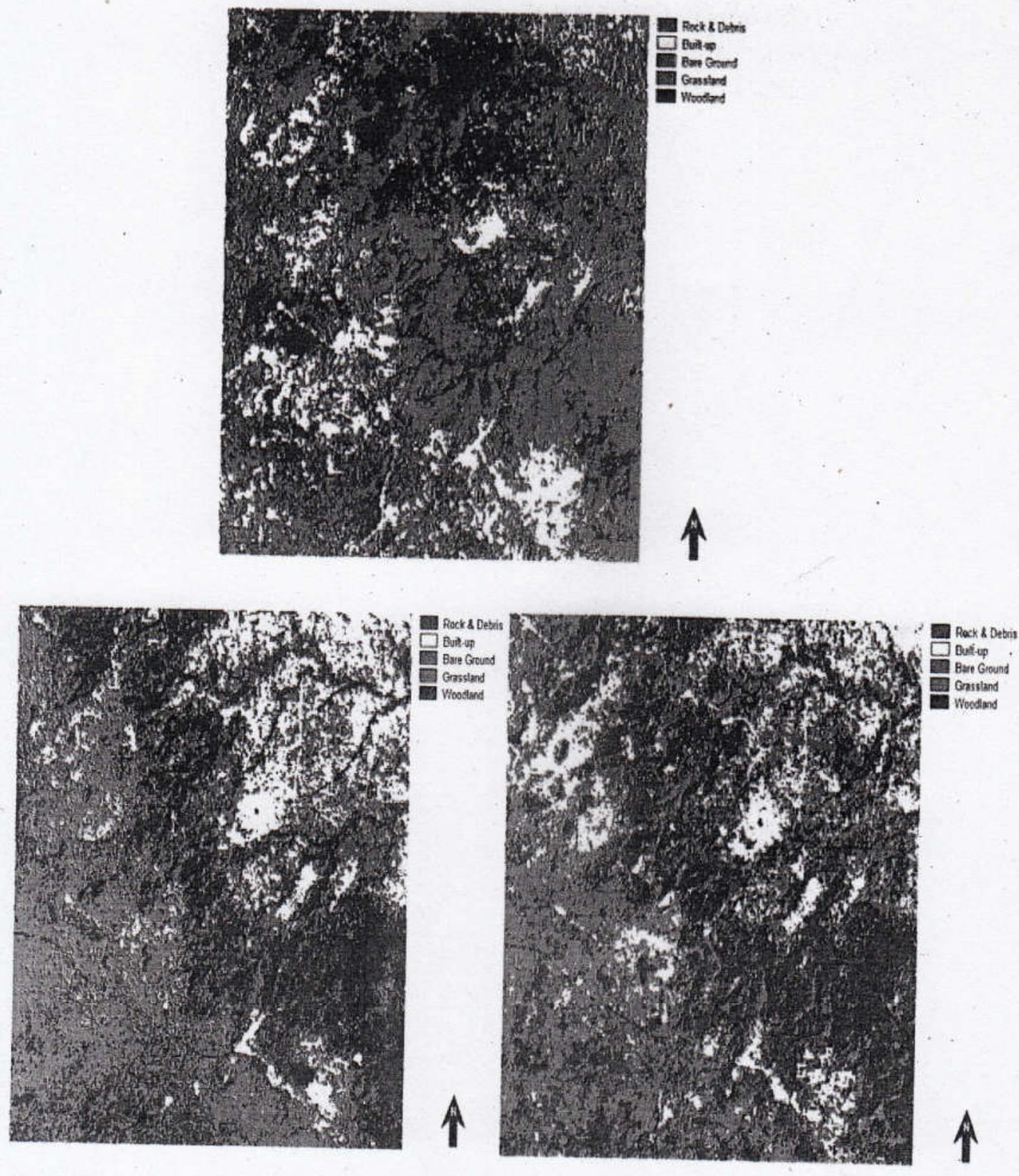

Annals of the Social Science Academy of Nigeria, No 20, 2015 
The Land Use/Land Cover classes delineated in this research are Built-up, Bare-ground, rock and debris, Grassland, Shrubs and woodland. The built up land consists of residential buildings, industrial buildings, educational and health facilities. The bare-ground consists of areas of exposed soil without vegetation; while rock and debris are heap of waste material from mines that looks like a hill. Again, grassland consists of areas where low green plants are the main vegetation; shrubs are areas with woody plants; and woodland consists of trees, shrubs and bushes.

Table 3: Area Occupied by the Land Use/Cover Classes for the 4 Epochs

\begin{tabular}{|l|l|r|r|r|r|r|r|r|r|}
\hline $\mathrm{S} / \mathrm{N}$ & $\begin{array}{l}\text { Landuse/Land } \\
\text { Cover classes }\end{array}$ & \multicolumn{2}{|c|}{1998} & \multicolumn{2}{|c|}{2002} & \multicolumn{2}{|c|}{2007} & \multicolumn{2}{c|}{2012} \\
\hline & & $\begin{array}{c}\text { Area } \\
\left(\mathrm{Km}^{2}\right)\end{array}$ & $\%$ & \multicolumn{1}{c|}{$\begin{array}{c}\text { Area } \\
\left(\mathrm{Km}^{2}\right)\end{array}$} & $\%$ & $\begin{array}{l}\text { Area } \\
\left(\mathrm{Km}^{2}\right)\end{array}$ & $\%$ & $\begin{array}{r}\text { Area } \\
\left(\mathrm{Km}^{2}\right)\end{array}$ & $\%$ \\
\hline 1 & Built-up & 13.7754 & 11.2 & 15.2775 & 12.4 & 15.7257 & 12.8 & 15.5169 & 12.6 \\
\hline 2 & Rock and debris & 7,038 & 5.7 & 3.5343 & 2.8 & 7.4682 & 6.1 & 4.3236 & 3.5 \\
\hline 3 & Bare-Ground & 29.637 & 24.1 & 34.1892 & 27.8 & 34.6041 & 28.2 & 34.8723 & 28.4 \\
\hline 4 & Grassland & 32.7294 & 26.7 & 35.701 & 29 & 29.8269 & 24.2 & 36.0742 & 29.4 \\
\hline 5 & Woodland & 39.6972 & 32.2 & 34.1748 & 27.7 & 35.2521 & 28.7 & 32.0895 & 26.1 \\
\hline 6 & Total & 122.8 & 100 & 122.8 & 100 & 122.8 & 100 & 122.8 & 100 \\
\hline
\end{tabular}

Source: From the Authors'2013 Fieldwork

Woodland occupied $39.7 \mathrm{~km}^{2}$ of land in 1998 decreased to $34.2 \mathrm{~km}^{2}$ in 2002, it increased to $35.3 \mathrm{~km}^{2}$ in 2007 and decreased to $32.1 \mathrm{~km}^{2}$ in 2012 . The drops could be attributed to increase in cultivation, fuel wood harvest and construction. Furthermore, grassland occupied $32.7 \mathrm{~km}^{2}$ of land in 1998, increased to $35.7 \mathrm{~km}^{2}$ in 2002 , decreased to $29.82 \mathrm{~km}^{2} 2007$ and rose to $36.07 \mathrm{~km}^{2}$ in 2012 . The rising and falling is due to upsurge and decrease in human activities like coal mining and agricultural activities among others. Also, rock and debris constituted $7.038 \mathrm{~km}^{2}$ in 1998 ; it then dropped sharply to $3.53 \mathrm{~km}^{2}$ in 2002 , rose to 7.46 $\mathrm{km}^{2}$ in 2007 and finally dropped again to $4.32 \mathrm{~km}^{2}$ in 2012 . The trend of events here alternates an increase, a drop, an increase again and a drop finally. It denotes the dynamic nature of human activities in the study area such coal 
mining and agricultural activities. Moreover, in 1998, built-up occupied $13.775 \mathrm{~km}^{2}$ then increased to $15.27 \mathrm{~km}^{2}$ in 2002 and further increased in 2007 to $15.72 \mathrm{~km}^{2}$, an indication of influx of people to the activity area; and it however dropped minimally to $15.51 \mathrm{~km}^{2}$ in 2012 due to transfer of labour as a result of the closure of the coal mining industry. There was a constant increase of houses probably as a result of the upsurge of human activities like mining, except in the last year when a drop occurred. And finally, bare-ground analysis showed that bare ground covers $29.6 \mathrm{~km}^{2}$ in 1998 rose to $34.1 \mathrm{~km}^{2}$ in $2002,34.6 \mathrm{~km}^{2}$ in 2007 and $34.8 \mathrm{~km}^{2}$ in 2012 respectively.

The results revealed that the study area got an increase in bare ground throughout the study epochs; the increase is attributed to reduction in vegetative cover as a result of coal extraction/processing and agricultural activities. The scattered vegetation, rock and debris and bare-ground represent a degraded landscape. Mining activities and agricultural activities to meet human needs lead to de-vegetation and soil erosion. Therefore, the observed land cover types are as a result of varying degree of human intrusion on the environment. In this study LANDSAT DATA has distinguished major land cover types, which is consistent with the capability of LANDSAT Data demonstrated elsewhere for mapping and monitoring land cover of environmentally degraded landscapes (Gala et. al. 2011; Fadhil; 2009 and Mehnaz; 2006). The finding here corroborates Meadows and Hoffman (2002) as well as UNEP (1997), who argue that loss of vegetation cover is probably the first visible form of land degradation.

\section{Figure 9: Showing the Land Use/Cover Change Dynamics of the Study Area}

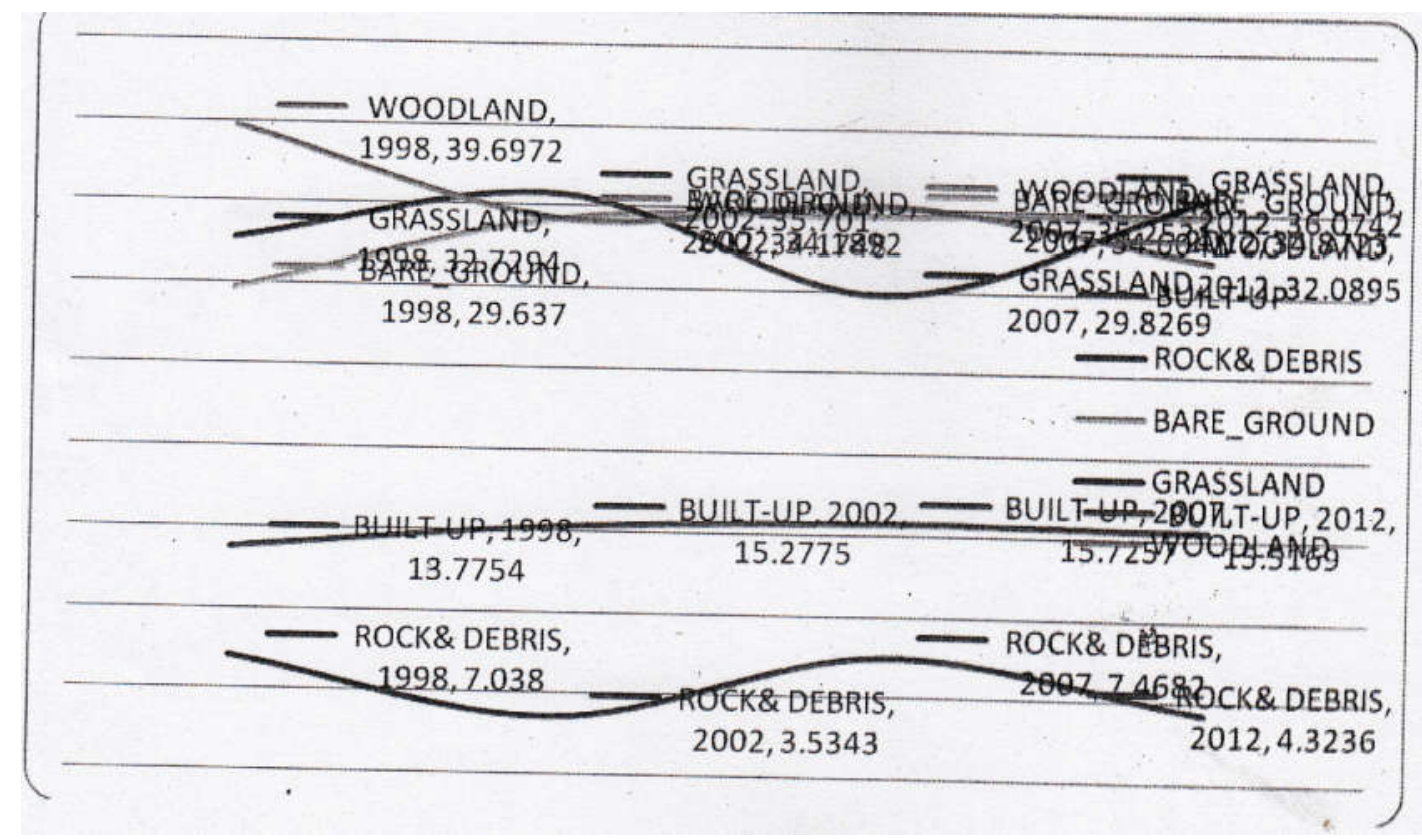

The quantity of land use/cover present for each epoch under study has been presented in Table 3. From table 3, it can be observed clearly what land use/cover classes have 
increased/decreased from one year to another. A graphical rendition of the change dynamics associated with each class is also presented in Figure 9. It is noteworthy that bare ground has increased steadily through the four study epochs (1998, 2002, 2007 and 2012) while vegetation decreases. This shows that anthropogenic activities have consistently increased leading to the creation of more paved surfaces. The remaining land uses did not poses a definite change trend but rather exhibited a haphazard change dynamics. This result agrees with Florencia (2003), Stocking and Murnaghan (2000), and Kakembo (1997) who argue that land degradation is shown by a serious depletion of vegetation cover, soil degradation and an increase in the proportion of bare land. The overall classification accuracy was $89.57 \%(1998), 79 \%(2002), 92 \%(2007)$ and $87.30 \%(2012)$.

\section{Estimation of Vegetation Cover Using Normalized Differential Vegetation Index (NDVI)}

\section{Figure 10: Vegetation Distribution in the Study Area Derived from the NDVI}
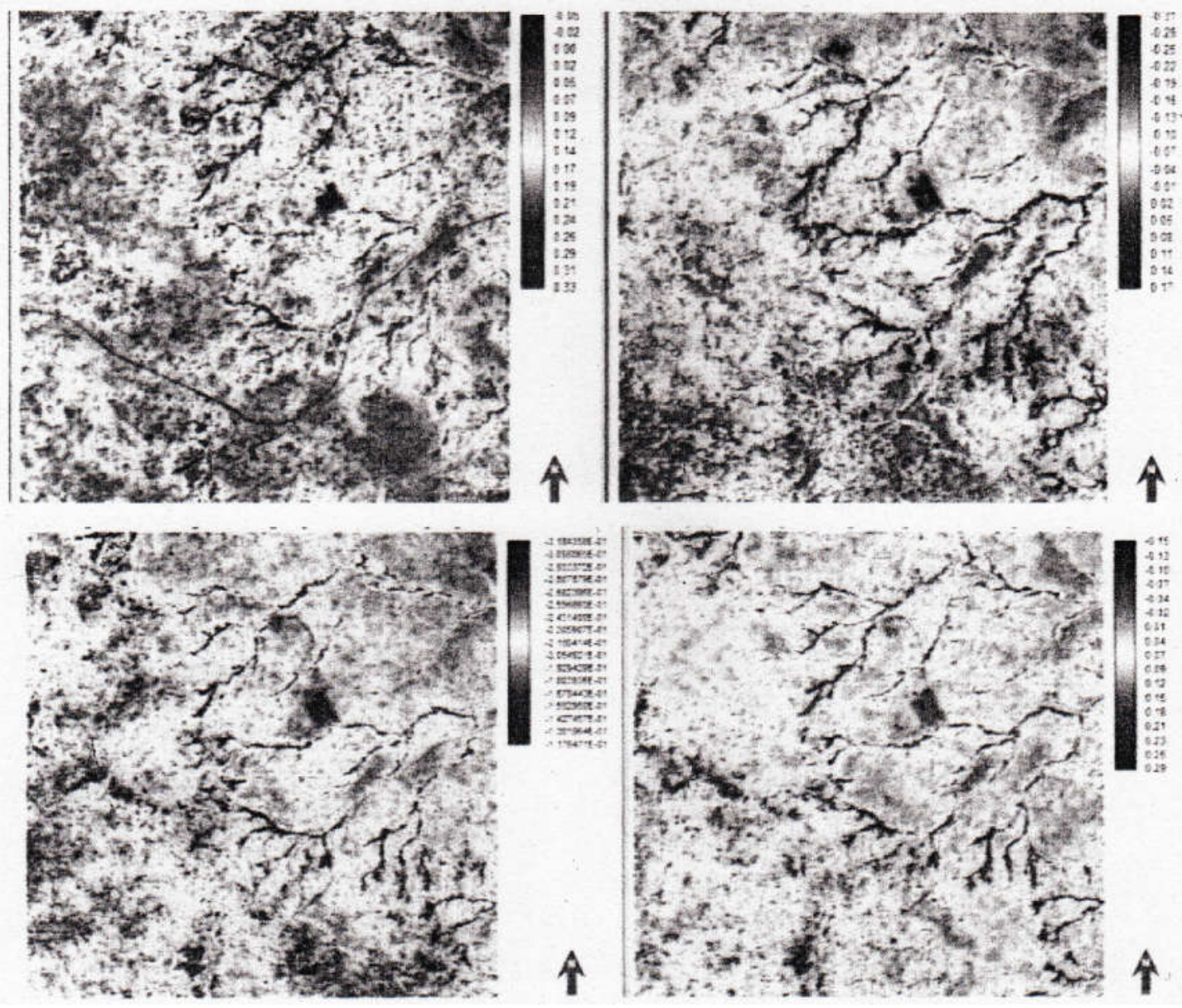

NDVI values were obtained in the range of -0.14 to 0.33 . The vegetation as revealed by the Ndvi results show that vegetation declined steadily between 1998 and 2007 and increased slightly in 2012. Field investigation reveals that the dynamics is as a result of 
changes in the intensity of coal mining and agriculture agricultural activities. The coal mine was active between 1998 and 2007 but was abandoned in 2012. Furthermore, Tasselled Cap Transformation was evaluated in this study. The tasseled cap brightness values were obtained in the range of 103-370; higher values are found in the built-up and bare ground areas. The lowest values are found within woodland and grassland areas. Tasseled cap greenness values where obtained in the range of-52 to 3.74, higher values were found in woodland and grassland areas while low values are found within bare ground and built up areas. Tasseled cap wetness (moistness) values were obtained in the range of -174 to 18.41 average values. Areas with low values are found within bare ground and built up areas. The higher values are found within woodland and grassland areas. The result revealed that the lower the soil moisture the lower the vegetation covers. 


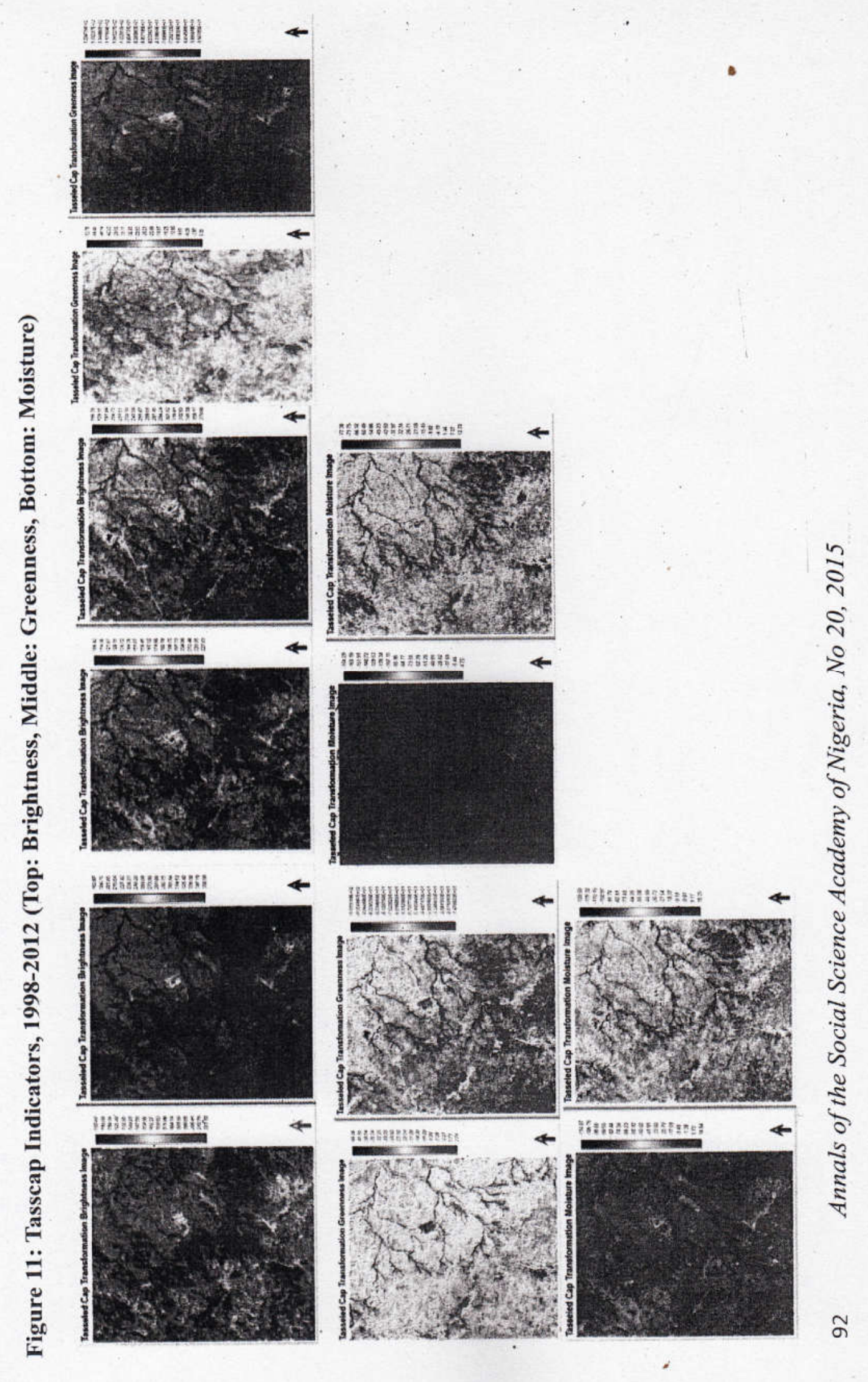


Figure 12: Composite Tasscap Indicators (Top: 1998-2002, Bottom: 2007-2012

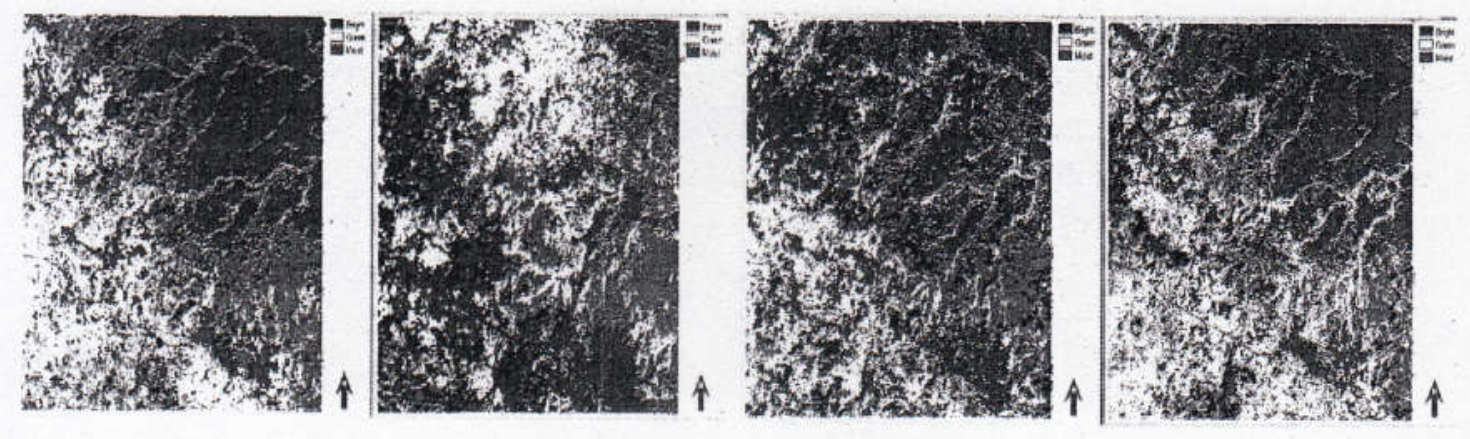

Source: Author Fieldword (2013) 


\section{Conclusion}

The results revealed that there was a continuous increase in bare ground and decline in vegetation throughout the study epochs. This is not unconnected to the anthropogenetic activities such as coal extraction/processing and agricultural activities currently plaguing the area leading to the creation and modification of the ecosystem with its attendant consequences on degradation and ecosystem perturbation. The study further revealed that about $42.1 \%$ of the land is currently undergoing different kinds of degradation. Again, the study establishes the correlation between the area occupied by non-degraded and area occupied by degraded area though an inverse relationship, hi view of the above, the study recommends that the map produced from this study should be used as a guide in the restoration and management of the ecological systems. However, since it is expensive, the restoration can be done gradually according to the severity of the degradation.

\section{References}

Adams, C.R., Eswaran, H. (2000). Global Land Resources in the Content of Food and Environmental Security, in Gwandes. P., (ed), Advances in Land Resources Management for the $20^{\text {th }}$ Century, p.655. New Delhi: Soil Conservation Society of India.

Anderson (1976) A Land Use and Land Cover Classification System_For Use with Remote Sensor Data. Geological Survey Professional Paper No. 964, U.S. Government Printing Office, Washington, D.C. p. 28.

Bai, Z.G., Dent, D.L., Olsson, I., Schaepman M.E. (2008). Global Assessment of Land Degradation and Improvement: Identification by remote sensing. Report 2008/01, ISRIC, Wagenongen.

Charles Udosen and Eshiett A.A. (2009) Research Journal of Applied Sciences 4(4): 142-147. Coppin, P., Jonckheere, I., Nackaerts, K., Muys, B., Lambin, E., (2004) Digital Change Detection Methods in Ecosystem Monitoring: A Review. International Journal of Remote Sensing 25: 1565-1596.

Fadhil, A.M., (2009) Land Degradation Detection using Geo-information Technology for Some Sites in Iraq, Journal of AL Nahrain University -Science (JNUS) 12(3), 94108 .

Faniran, A. and Ojo, O. (1980) Man 's Physical Environment. London, Heinemann. FAO (2005) Agro-ecological Zoning and GIS Application in Asia with Special 
Emphasis on Land Degradation Assessment in Dry Lands (LADA). Proceedings of a Regional Workshop, Bangkok, Thailand 10-14 November, 2003.Retrieved August 31, 2011 from www.fao.org

Florencia, F., (2003) Land Cover Change in Rural Areas of the Forest-Steppe Ecotone of Andean Patagonia, Argentina: Utilising Landsat Data for the Detection and Analysing the Change'. Unpublished Master's thesis; Lund University: Sweden.

Gala, T.S., Pazner M. and Beyenes S. (2011) Evaluating Biophysical Attributes of Environmentally Degraded Landscapes in Northern Ethiopia using LANDSAT ETM data and GIS; Ethiopian Journal of environmental studies and management 4(1).

Kakembo, V. ( 1997) A Reconstruction of the History of Land Degradation in Relation to Land Use Change and Land Tenure in Peddie District, former Ciskei'. Unpublished Master's thesis; Rhodes University; Grahamstown.

Kiage L. M., Liu K .B., Walker N. D., Lam N. and Huh O.K.(2007) Recent Land Cover/ Use Change Associated with Land Degradation in the Lake Baringo Catchment, Kenya, East Africa: Evidence from Landsat TM and ETM+, Int. J. Remote Sensing 28(19) 42854309.

Meadows, M.E., Hoffman, M.T., (2002) The Nature, Extent and Causes of Land Degradation in South Africa: Legacy of the past, lessons for the future? Area 34:428237.

Mehnaz R. et,al, (2010) Geospatial Tools for Assessing Land Degradation in Budgam district, Kashhmir Himalaya India, Department of Geology and Geophysics, University of Kashmir, Sriinagar 190006, India.

Moody R, and Panos S.P. (1997) Environmental Assessment of Mining Projects. http:/ /www.worldbank.org/mining.xlsO.

Omali A. O. and Egboka B. C. E. (2011) Physico-Chemical Assessment of Water around Okaba Coal Mining, Kogi State, Nigeria. Natural and Applied Journal, Vol. 12 No. 2.Retrieved 29 August 2013 from www.naasiournal-ng.org.

Snel M. and Bot A. (2003) Draft paper: Suggested Indicators for Land Degradation Assessment in Dry lands. FAO, Rome.

Stocking, M.A., Murnaghan, N. (2000) Land Degradation - Guidelines for Field Assessment. Available at: http://www.unu.edu/env/plec/l-degrade/index-toc.html; Accessed 14/01/2008.

Symeonakis E. and Drake N. (2004) Monitoring Desertification and Land Degradation 
over Sub-Saharan Africa; Int. J.Remote Sensing 25(3) 573-595.

Tauli-Corpuz, V.(1997) The Globalization of Mining and its Impact and Challenges for Women. Ihttp: //www.twnside.org.sg/bookstore.Html.

Kebiru, U. (2008) Problems and Prospects of Okaba coal mining Industry, Unpublished B.Sc. Project Submitted to Department of Geography and Planning, Kogi State University, Anyigba, Nigeria.

UNEP (1992) World Atlas of Desertification, Edward Arnold, London.

UNEP (1997) Industry and Environment, Mining and Sustainable Development. http:// www.uneptie.orR/vol20no4.htmO.

UNEP (2008) Africa: Atlas of our Changing Environment. Division of Early Warning and Assessment (DEWA). United Nations Environment Programme (UNEP). Nairobi, 00100, Kenya. 